\title{
Effect of Gamma Radiation on Graft Copolymerization of Rice Straw Cellulose-Acrylamide Monomer
}

\author{
${ }^{1}$ Thurein Kyaw, and ${ }^{2}$ Khin Khin Lay
}

\begin{abstract}
Agriculture is the main industry for Myanmar, where rice is the main staple food and rice straw is the most abundant agricultural waste. However agricultural productivity in Myanmar, comparing with other South East Asia countries, is considerably low because local agricultural systems still follow the traditional methods that utilise the available natural resources combined with improved cultural practices. To fulfil the major needs for improving agricultural productivity and to recycle the abundant agricultural wastes into useful products for agricultural sector in Myanmar, current research is based on modification of rice straw cellulose through radiation graft copolymerization with acrylamide monomer for the synthesis of hydrogel which can be used as a controlled release fertiliser. Rice straw cellulose was prepared by soda process. Morphological structures of the cellulose pulp and grafted copolymer were analysed by Scanning Electron Microscope (SEM). Monomer concentration was varied from $1 \mathrm{M}$ up to $2 \mathrm{M}$, and various radiation doses $(10-50 \mathrm{kGy})$ were applied for grafting. Fourier Transfer Infrared (FTIR) was used to analyse the original cellulose and grafted cellulose. The effect of radiation dose and monomer concentration on grafting efficiency, gel fraction, crosslink density, and swelling degree were studied. The grafting efficiency and gel fraction increased with increasing in radiation dose. The higher in crosslink density, which is directly proportional to increasing in radiation dose, led to decreasing in swelling degree. Crosslink density increased with the increment in monomer concentration and swelling degree, which is inversely proportional to crosslink density, decreased with the increment in monomer concentration.
\end{abstract}

Keywords-Gamma Radiaion Effect, Hydrogel, Radiation Copolymerization, Rice Straw Cellulose.

\section{INTRODUCTION}

Three main soil groups are agriculturally important in Myanmar. They are Alluvial, with $50 \%$ of total sown area, that are mostly found in river basin and delta regions, Black Soil, with $30 \%$ of total sown area, that can be found in dry regions, and Red Laterite, with $20 \%$ of total sown area, that are found in lower Myanmar associated with undulating topography [10]. Although Myanmar is an agricultural based country, agricultural productivity is low compared with other South-East-Asia countries. It may be because present agricultural systems in Myanmar still follow the traditional

Manuscript received Apr. 29, 2016. This work was supported in part by Universal Researchers (UAE).

${ }^{1}$ Author is with the Department of Nuclear Engineering, Mandalay Technological University, Ministry of Education, Myanmar

${ }^{2}$ Author is with the Department of Nuclear Engineering, Mandalay Technological University, Ministry of Education, Myanmar methods that utilise the available natural resources combined with improved cultural practices. Dry zone regions that are resource-poor areas, are suffering from scarcity of water because of low annual rainfall and thin vegetation cover. Also, in undulating land, composed mainly of clay and sandy loams, natural fertility is low [10]. Therefore improvement in utilization of water resources and nutritive fertilizers become important factors in the country. Studies show that about $40 \%$ to $70 \%$ of nitrogen and nitrogen compounds loaded in fertilisers cannot be absorbed by plant's root and are permeated into the environment [6]-[1].

One early approach to increase the fertilizer effectiveness and efficiency is modification of the product into slow-release fertilizer (SRF) form. As the rate, the pattern and the duration of release in SRF system cannot be controlled well, another effort is on the synthesis of controlled release fertilizer (CRF) based on coated or encapsulation fertilizer such as resin, rubber, formaldehyde and sulphur. But one problem is the higher cost of producing coated or encapsulated fertilizers compared with that of conventional fertilizers. These situations are a force led to applications of hydrogel-type controlled release fertilizers.

Hydrogels are three-dimensional cross-linked networks and they can be used in many kinds of applications including biotechnology, biomedicine, pharmaceutical, veterinary, agriculture and other fields. If they are used as a controlled release system, the lost amount of ingredients in fertiliser by permeation to the environment can be controlled by changing the network structure in them. There are also advantages of using hydrogels in CRF such as increment in fertiliser efficiency, reduction of soil toxicity, and enhancement in soil condition.

Natural biopolymer such as cellulose, chitin, chitosan and starch are good precursors in hydrogel preparation for they are nontoxic, biodegradable, renewable and abundant in nature. Among these, cellulose extracted from rice straw is more favourable because of its great cross-linking ability in the presence of abundant hydroxyl $(\mathrm{OH})$ groups [1].

Radiation grafting is one of the most favourable methods among different methodologies for graft copolymerization such as chemical, photochemical and high energy radiation initiation techniques. For it can be easily handled at room temperature, provides large penetration in the polymer matrix, gives the formation for initiating grafting rapidly and uniformly, and needs no further chemical initiation.

As befitting one of the largest rice-producing countries in the world, rice straw is the most abundant waste in Myanmar. The 
main aim of this research is to fulfil the major needs for improving agricultural productivity and to recycle the abundant agricultural wastes into useful products by applying peaceful use of nuclear techniques for development in productive, profitable, and sustainable agricultural systems without the use of costly hazardous synthetic agricultural chemicals.

In the present study, Gamma radiation effects on the graft copolymerization of rice straw cellulose-acrylamide monomer for the synthesis of hydrogel were studied.

\section{MATERIALS AND METHOD}

\section{A. Materials}

Rice straw was obtained from rice field in $\mathrm{Pa}$ Thein Gyi, Mandalay region, Myanmar. Acrylamide monomer was analar grade, and sodium hydroxide (flake type), acetic acid, ethanol and bleaching powder were used.

\section{B. Preparation of Cellulose Pulp from Rice Straw}

Rice straw was collected from rice field in Pa Thein Gyi, Mandalay region. Chaff and impurities were primarily cleaned and the straw was ground to get about 60 mesh particle size. The prepared straw was soaked in water for about 6 to 8 hours in order to remove dirt and water-soluble impurities. Cellulose pulp was made by soda process [4].

\section{Graft Copolymerization of Cellulose-Acrylamide using} Gamma Radiation

Cellulose was mixed with distilled water and stirred at 400 rpm at room temperature for one hour. Different concentrations of acrylamide monomer (1M, $1.5 \mathrm{M}$ and $2 \mathrm{M})$ were used for the experiments. Acrylamide was added to the cellulose mixture and $350 \mathrm{~cm}^{3}$ round containers were used for the mixed samples to be irradiated by gamma radiation. Graft copolymerization of cellulose-acrylamide monomer was carried out using Gamma Chamber (Cobalt-60, GC-5000) with the variation of doses ranging from $10 \mathrm{kGy}$ to $50 \mathrm{kGy}$.

\section{ANALytiCAl MethodS}

\section{A. Scanning Electron Microscope (SEM)}

Scanning electron microscope (SEM) was used to compare the morphological structures of original rice straw cellulose and radiation grafted copolymer.

\section{B. Determination of Grafting Efficiency}

Cellulose-acrylamide graft copolymers were washed with deionised water and separated. The product was dewatered with ethanol and dried in an oven at $65^{\circ} \mathrm{C}$ for about 24 hours. Grafting efficiency (GE) was determined using gravimetry and calculated by the following equation.

$$
G E=\frac{W_{h}-W_{s}}{W_{m}} \times 100 \%
$$

$\mathrm{W}_{\mathrm{h}}$ is weight of cellulose-acrylamide graft copolymer, and $\mathrm{W}_{\mathrm{s}}$ is weight of cellulose, and $\mathrm{W}_{\mathrm{m}}$ is weight of acrylamide monomer.

\section{Determination of Gel Fraction}

For gel fraction measurement, the irradiated samples were immersed and extracted in deionised water for about 48 hours at ambient temperature, and insoluble residues were dried at $60^{\circ} \mathrm{C}$ for 3 hours. Following equation was used to calculate the gel fraction (GF).

$$
G F=\frac{W_{1}}{W_{0}} \times 100 \%
$$

$\mathrm{W}_{0}$ is the initial weight of the sample and $\mathrm{W}_{1}$ is weight of the insoluble residue.

\section{Determination of Crosslink Density}

The crosslink density was determined by using swelling technique according in conjunction with the Flory-Rhener theory [11]. The equilibrium swelling theory of Flory-rhener proposed for sample polymer network is expressed in the following equation.

$$
\rho_{e}=\frac{\left[\ln \left(1-v_{2, s}\right)+v_{2, s}+\chi_{1}\left(v_{2, s}\right)^{2}\right] / V_{1}}{\left[v_{2, s}^{1 / 3}-\frac{v_{2, s}}{2}\right]}
$$

where $\chi_{1}$ is dimensionless Flory-Huggins polymer-solvent interaction term for cellulose-water $0.44, \mathrm{~V}_{1}$ is the molar volume of solvent, and $v_{2, \mathrm{~s}}$ is the amount of liquid which can be absorbed by hydrogel and it is expressed as the ratio of the polymer volume $\left(\mathrm{V}_{\mathrm{p}}\right)$ to the swollen gel volume $\left(\mathrm{V}_{\mathrm{g}}\right)$. It can be expressed as:

$$
v_{2, s}=\frac{V_{p}}{V_{g}}
$$

where $\mathrm{V}_{\mathrm{p}}$ refers to polymer volume and $\mathrm{V}_{\mathrm{g}}$ is the swollen gel volume.

\section{E. Determination of Swelling Degree}

Hydrogel is firstly immersed in deionised water for about 48 hours at room temperature on a mixer. After swelling, the copolymerized hydrogel product is filtered and the swelling degree (SD) of the product is calculated as shown in the following equation.

$$
S D=\frac{W_{s s}-W_{d}}{W_{d}} \times 100 \%
$$

$\mathrm{W}_{\mathrm{ss}}$ is weight of hydrogel in swollen state and $\mathrm{W}_{\mathrm{d}}$ is the weight of dry hydrogel [12].

\section{F. Fourier Transformed Infrared Spectroscopy (FTIR)}

The FTIR spectrum was used to identify functional group of the active components based on the peak value in the region of infrared radiation. The FTIR spectra of the original cellulose 
and grafted cellulose-acrylamide were recorded by FTIR Spectrophotometer (IR-Prestige-21, Shimadzu, Japan) in the wave number range $550-4000 \mathrm{~cm}^{-1}$. The FTIR spectrum was taken in a transmittance mode.

\section{RESULTS AND DISCUSSIONS}

\section{A. Scanning Electron Microscope (SEM)}

The scanning electron microscopes of rice straw cellulose and grafted copolymer hydrogels are shown in Fig 1.

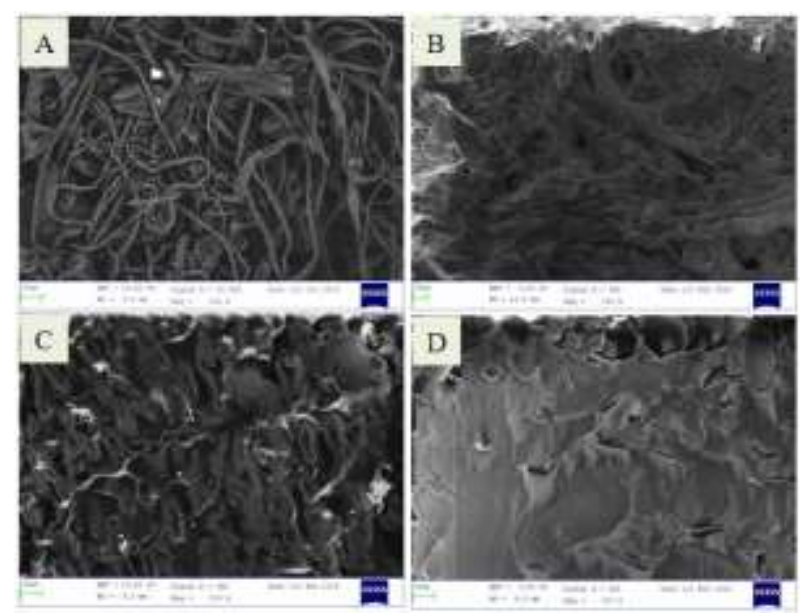

Fig. 1. SEM Pictures of (A) Original Rice Straw Cellulose, (B) Cellulose Acrylamide with Low Grafting, (C and D) Cellulose-Acrylamide with High Grafting

The morphology of rice straw cellulose and grafted copolymer hydrogel were examined by means of scanning electron microscope (SEM) with the aim of detecting qualitatively the presence of connected micro porosity.

According to the figures, it can be seen that interconnected micro porosity seems to be present after radiation grafting of acrylamide monomer onto the cellulose backbone. Interconnected pores provided more available regions for the diffusion of water molecules, and thus, the hydrogel may demonstrate a higher water absorption capacity.

\section{B. Effect of Radiation Dose on Grafting Efficiency and Gel Fraction}

The grafting efficiency and gel fraction were investigated with different irradiation doses ranging from 10 to $50 \mathrm{kGy}$ by using $2 \mathrm{M}$ concentration of monomer as shown in Table 1.

TABLE I: EFFECT OF RADIATION DOSES ON GRAFTING EFFICIENCY AND GEL FRACTION

\begin{tabular}{ccc}
\hline \hline $\begin{array}{c}\text { Radiation Doses } \\
(\mathbf{k G y})\end{array}$ & $\begin{array}{c}\text { Grafting Efficiency } \\
\mathbf{( \% )}\end{array}$ & $\begin{array}{c}\text { Gel Fraction } \\
(\mathbf{\%})\end{array}$ \\
\hline 10 & 90.815 & 81.088 \\
\hline 20 & 91.220 & 82.948 \\
\hline 30 & 91.539 & 84.103 \\
\hline 40 & 91.694 & 85.404 \\
\hline 50 & 92.034 & 88.302 \\
\hline
\end{tabular}

In Table 1, it can be seen that the grafting efficiency increased with increasing radiation dose. An increase in the radiation dose enhances the formation of radicals in the reaction mixture of acrylamide monomer, cellulose, and water. The high radiation dose can induce enough active grafting sites on the cellulose backbone for the grafting of monomer. Therefore increasing the total dose reduces the homopolymer content and increases the grafting efficiency.

Gel fraction increases as radiation dose increases. It may be due to the increased number of free radicals on the cellulose chain. The free radicals can form more crosslinks between cellulose chains and that leads to form three-dimensional network.

\section{Effect of Radiation Dose on Crosslink Density and Swelling Degree}

Effect of radiation dose on the crosslink density and the swelling degree of cellulose-acrylamide graft copolymer hydrogels are showed in Table 2.

TABLE II: EFFECT OF RADIATION DOSES ON CROSSLINK DENSITY AND SWELLING DEGREE

\begin{tabular}{ccc}
\hline \hline $\begin{array}{c}\text { Radiation Doses } \\
(\mathbf{k G y})\end{array}$ & $\begin{array}{c}\text { Crosslink Density } \\
\left(\mathbf{m o l} / \mathbf{c m}^{\mathbf{3}}\right)\end{array}$ & $\begin{array}{c}\text { Swelling Degree } \\
(\mathbf{\%})\end{array}$ \\
\hline 10 & 0.00385 & 834.45 \\
\hline 20 & 0.00189 & 1050.50 \\
\hline 30 & 0.00792 & 725.33 \\
\hline 40 & 0.00535 & 760.85 \\
\hline 50 & 0.00598 & 742.92 \\
\hline
\end{tabular}

According to the results showed in Table 2, crosslink density decreases as radiation dose increases from 10 to $20 \mathrm{kGy}$. But it can be seen that the crosslink density decreases when radiation dose increased again from 20 to $30 \mathrm{kGy}$. It can be explain that the initial radiation dose cannot produce enough free radicals which can form crosslinks between cellulose chains. However the crosslink density at $30 \mathrm{kGy}$ may be said to be a saturation point or maximum crosslink density. After that, further increment in radiation dose does not affect remarkably on the cellulose-acrylamide graft copolymer.

It was found that the swelling of hydrogel increased with the increased radiation dose from 10 to $20 \mathrm{kGy}$. But the swelling degree decreased by increasing radiation dose from 20 to 30 $\mathrm{kGy}$. These could be explained that the increasing radiation dose enhances the number of free radicals on the cellulose chain and, therefore, form more cross-linking between cellulose chains. Higher in crosslink density reduces the free volume available for swelling by increasing the tightness of the network structure [6].

\section{Effect of Acrylamide Concentration on Grafting Efficiency and Gel Fraction}

The effect of acrylamide monomer concentration on the grafting efficiency and gel fraction of the hydrogels was investigated at $20 \mathrm{kGy}$ of gamma radiation dose as shown in Table 3.

TABLE III: EFFECT OF ACRYLAMIDE CONCENTRATION ON GRAFTING EFFICIENCY AND GEL FRACTION

\begin{tabular}{ccc}
\hline \hline $\begin{array}{c}\text { Concentration } \\
(\mathbf{M})\end{array}$ & $\begin{array}{c}\text { Grafting Efficiency } \\
(\boldsymbol{\%})\end{array}$ & $\begin{array}{c}\text { Gel Fraction } \\
(\boldsymbol{\%})\end{array}$ \\
\hline 1 & 90.179 & 80.865 \\
\hline 1.5 & 90.850 & 81.595 \\
\hline 2 & 91.220 & 82.948 \\
\hline \hline
\end{tabular}


The results show that the grafting efficiency and gel fraction increased with the increasing monomer concentration from $1 \mathrm{M}$ up to $2 \mathrm{M}$. This behaviour can be attributed to the increase of monomer concentration in the surrounding of cellulose backbone and it can enhance chances for molecular collisions of the reactants [6].

\section{E. Effect of Acrylamide Concentration on Crosslink Density} and Swelling Degree

The effect of acrylamide monomer concentration on the crosslink density and swelling degree of the hydrogels was investigated at $20 \mathrm{kGy}$ of gamma radiation dose as shown in Table 4.

TABLE IV: EFFECT OF ACRYLAMIDE CONCENTRATION ON CROSSLINK DENSITY AND SWELLING DEGREE

\begin{tabular}{ccc}
\hline \hline $\begin{array}{c}\text { Concentration } \\
(\mathbf{M})\end{array}$ & $\begin{array}{c}\text { Crosslink Density } \\
\left(\mathbf{m o l} / \mathbf{c m}^{\mathbf{3}}\right)\end{array}$ & $\begin{array}{c}\text { Swelling Degree } \\
(\mathbf{\%})\end{array}$ \\
\hline 1 & 0.00089 & 1190.59 \\
\hline 1.5 & 0.00125 & 1108.35 \\
\hline 2 & 0.00189 & 1050.50 \\
\hline \hline
\end{tabular}

In Table 4, it can be seen that, at higher concentration of monomer, the free radicals come closer than lower concentration of monomer and that tends to form more cross-links in the cellulose chains. Therefore, with increased cross-linked density, swelling ratio decreased due to reduced vacant space of cross-linking network for free solvent to enter into it.

\section{F. Characterization of Rice Straw Cellulose and Grafted Copolymers using FTIR Spectroscopy}

The FTIR spectrum of the original cellulose of rice straw was shown in Fig. 2 and the spectrum of radiation grafted copolymer was presented in Fig. 3.

In FTIR studies, the mid-infrared spectrum $\left(4000-400 \mathrm{~cm}^{-1}\right)$ can be approximately divided into four regions; $\mathrm{X}-\mathrm{H}$ stretching region $\left(4000-2500 \mathrm{~cm}^{-1}\right)$, the triple-bond region (2500-2000 $\left.\mathrm{cm}^{-1}\right)$, the double-bond region $\left(2000-1500 \mathrm{~cm}^{-1}\right)$ and the fingerprint region $\left(1500-600 \mathrm{~cm}^{-1}\right)$ [7].

Fundamental vibrations in the $4000-2500 \mathrm{~cm}^{-1}$ region are due to $\mathrm{O}-\mathrm{H}, \mathrm{C}-\mathrm{H}$ and $\mathrm{N}-\mathrm{H}$ stretching. O-H stretching produces a broader band and $\mathrm{N}-\mathrm{H}$ stretching is usually observed between 3400 and $3300 \mathrm{~cm}^{-1}$ [7]. According to the results of FTIR spectroscopy, spectra of both rice straw cellulose and grafted cellulose showed nearly the same profile. However, the intensities of the absorption bands were different.

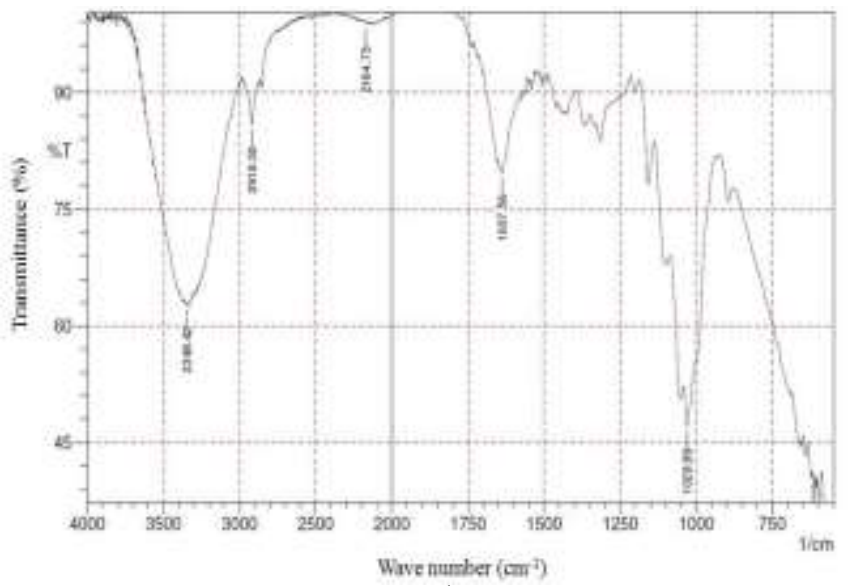

Fig. 2. The FTIR spectra $\left(4000-550 \mathrm{~cm}^{-1}\right)$ of the original rice straw cellulose

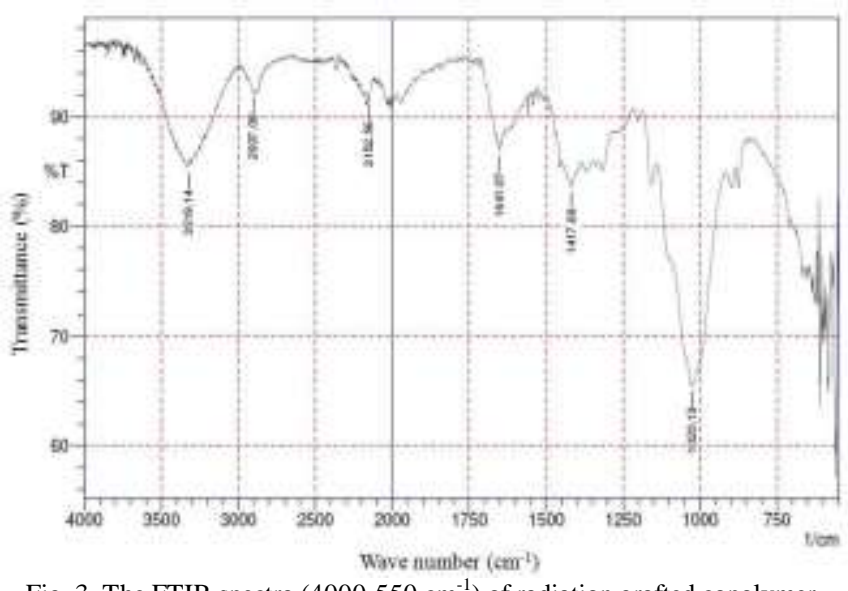

Fig. 3. The FTIR spectra $\left(4000-550 \mathrm{~cm}^{-1}\right)$ of radiation grafted copolymer

In Fig. 2, the absorption peak at $3348.4 \mathrm{~cm}^{-1}$ is assigned to the stretching of $-\mathrm{OH}$ groups, which was diminished after graft-copolymerization. It can be explained that the partial hydrogen bond of cellulose was destroyed enhancing the new formation of cross-links with acrylamide monomer. The changed spectra can be seen with the peaks at $3319.14 \mathrm{~cm}^{-1}$ in Fig. 3. These bands indicated the N-H stretching of the amide bands, which are characteristics of the $-\mathrm{CONH}_{2}$ group present in the acrylamide monomer [5]-[6].

The another obvious characteristic of the grafted cellulose spectrum which is distinguished from the spectrum of the original cellulose in Fig 2 (at $2184.73 \mathrm{~cm}^{-1}$ ) was the sharp presence of absorption bands at $2152.56 \mathrm{~cm}^{-1}$ in Fig. 3, which indicated the presence of amide secondary amine group [5]-[6]. These changes provided strong evidence of the grafting of acrylamide monomer onto cellulose.

The absorption bands at $1637.56 \mathrm{~cm}^{-1}$ in original cellulose and $1641.07 \mathrm{~cm}^{-1}$ in grafted copolymer are assigned to the functional group that is present in the lignin. The presence of spectral bands in the range of $1000-1500 \mathrm{~cm}^{-1}$ indicated the characteristic of aloxy group of cellulose. The bands observed in the finger print region at $1020.13 \mathrm{~cm}^{-1}$ in Fig. 3 are typically related to the structural characteristics of cellulose and hemicellulose. 


\section{CONCLUSIONS}

Rice straw cellulose pulp was successfully prepared by soda process. Comparison of the morphological structures of rice straw cellulose and radiation grafted copolymer hydrogel showed that cellulose and acrylamide monomer were well grafted after gamma irradiation. Therefore rice straw cellulose was successfully modified by using radiation grafting technique. FTIR analysis also showed that acrylamide had been grafted onto cellulose. The higher the radiation dose the higher the grafting efficiency of cellulose-acrylamide hydrogel. However, swelling degree was found to be inversely proportional with radiation doses. The increasing of acrylamide monomer concentration increased the grafting efficiency but also inversely proportional to the swelling degree. The radiation induced graft copolymer showed considerably good swelling behaviour, and it can be said that the cellulose graft copolymer can be used in applications where swelling is necessary.

\section{ACKNOWLEDGMENT}

I would like to express heartfelt gratitude to Dr. Khin Khin Lay, my supervisor and main source of inspiration, for her tireless, interest, encouragement and patience on this research work. I also thank to Dr. Aye Aye Toe and other technical staff members in the analytical laboratory at Pyin Oo Lwin (GTI) for the help in SEM and FTIR analysis methods. My sincere gratitude to Dr. Tin Tin Myint, other teachers and friends from Department of Nuclear Engineering, Mandalay Technological University for their helpful facilities and suggestions. I would like to express special thanks to Daw Mi Cho Cho, principal scientist, and other technical staff members in the Department of Atomic Energy, Yangon for the permission and help for gamma chamber application.

\section{REFERENCES}

[1] Hekmat, A., Barati, A., Frahani, E.V., and Afraz, A., 2009, "Synthesis and Analysis of Swelling and Controlled Release Behaviour of Anionic sIPN Acrylamide based Hydrogels", World Academy of Science, Engineering and Technology Journals No. 56.

[2] Swantomo, D., Megasari, K., Saptaaji, R., 2008, "Pembuatan Komposit Polimer Superabsorben Dengan Mesin Berkas Elektron", Journal Forum Nuklir (JFN) Vol. 2 No. 2.

[3] Y.K. Bhardwaj, V. Kumar, A. Acharya and S. Sabharwal, “IAEA-TECDOC-1465”, IAEA, Vienna (2005) 87.

[4] P. Bhaskara Rama Murti and T. R. Seshadri, 1940, "Paper Pulp From Annual Crops".

[5] D. Swantomo, Rochmadi, K.T. Basuki and R. Sudiyo, "Synthesis and Characterization of Graft Copolymer Rice Straw Cellulose-Acrylamide Hydrogels Using Gamma Irradiation".

[6] D. Swantomo, Kartini Megasari, "Synthesis of Controlled Release Fertilizers Based on Smart Biodegradable Hydrogel Cellulose-Vinyl Monomers using Radiation".

[7] Barbara Stuart, "Infrared Spectroscopy: Fundamentals and Applications", John Wiley \& Sons, Ltd, 2004.

[8] He, Y., Pang, Y., Liu, Y., Li, X., and Wang, K., 2008, "Physiochemical Characterization of Rice Straw Pretreated with Sodium Hydroxide in the Solid State for Enhancing Biogas Production" Energy and Fuels Vol. 22, 2775-2781.
[9] Viera, r. G. P., Filho, G. R., Assuncao, R. M. N., Da, S., Meireless, C., Viera, J.G., and De Oliveria, G. S. 2007. "Synthesis and Characterization of methylcellulose from sugar cane bagasse cellulose," Carbohydrate Polymers 67, 182-189.

[10] U Myint Thein, Director-General (Retd), Ministry of Agriculture and Irrigation, Yangon, "Accessment of the current state of agriculture, forestry and marine resources, VII. Myanmar".

[11] P.J. Flory, Principles of Polymer Chemistry, Cornell University Press, New York (1953) 579

[12] N. Nagasawa, T. Yagi, T. Kume and F. Yoshii, Carbohydr. Polym. 58 (2004) 110. 